\title{
Creating educational networking opportunities with Scoop.it
}

The adoption of social media technologies by higher education institutions reflects a significant change in learning paradigms. The traditional classroom model in which instructors were the sole source of information and knowledge is being replaced by a social constructivist model that allows learners to work together to share and create content. This study explores the potential of the digital curation platform Scoop.it as a networking tool among a group of first year ICT students. It will be shown that Scoop.it is a useful platform for the creation and sharing of information resources with other students and the wider community. Scoop.it facilitates the creation of networks for information sharing and knowledge building, which will be referred to as educational networking, but was less successful as a platform for forming social connections.

\section{Introduction}

Higher education institutions have been increasingly attracted to social media technologies for the purpose of engaging and motivating students to become more active learners (Hughes, 2009). In recent years there has been a surge in the integration of social media tools into the learning process (Ebner, Lienhardt, Rohs \& Meyer, 2010; Schroeder, Minocha \& Schneider, 2010). Using social media platforms, such as Facebook and Twitter, in educationally relevant ways has been found to create a culture of engagement between students who interact with each other around academic and co-curricular issues (Junco, Heiberger \& Loken, 2010). Building on this premise, it was proposed that the integration of the digital curation tool Scoop.it into the curriculum would enable students to network with each other and the wider community, for both social and educational purposes. While it could be argued that all interaction is social, including interaction that is related to study and/or assessment, social networking in this study is trivialized and will be referred to as informal, social discussion that is not work-related. Educational networking, in contrast, refers to the sharing of information resources and/or discussions about the assessment task or other work-related matters. 
In this study, Scoop.it was introduced into a first year, first semester, Information Communication Technology (ICT) course, being taught across three demographically diverse campuses of a metropolitan university. This platform, which can be integrated with a user's Facebook and Twitter accounts, although this was not compulsory for the assessment task, allowed the students to interact and network with other students and the wider community on an area of ICT they were interested in. Scoop.it is driven by a topic-based search engine, as opposed to a 'pure' social networking platform such as Facebook which is used primarily to 'Find Friends'. The students in this study nonetheless networked for educational purposes; they engaged and collaborated with other students and the wider community for the purpose of accumulating resources for their Scoop.it pages. This is distinct from the type of networking that is typically undertaken on social networking sites, which may include, for example, sharing photos and posting status updates. The results of this study indicate that Scoop.it allowed students and the wider community to collaborate, converse, share knowledge and help each other gain a better understanding of subject matter through online discussion in the form of comments and through the sharing of information resources. That is, Scoop.it allowed the students to network for educational purposes but was a less desirable medium for social interaction.

\section{Background}

\subsection{Digital curation}

Many definitions of digital curation have been proposed since the inception of a number of Web 2.0 tools self-proclaimed as digital curation platforms including Scoop.it, Storify, Pearltrees, and Pinterest to name a few. Erin Scime (2009) defines curation as the active, editorial component of aggregation, while Steve Wheeler (2010) likens the role of the digital curator to their museum counterparts, who trade in specialized, focused content. According to Steve Rosenbaum (2010), digital curation involves 'the act of human editors adding their 
work to the machines that gather, organize, and filter content'.

These definitions, however, do not take into account the meta-cognitive processessynthesizing, analyzing, and prioritizing - that are at work in the curation of digital content. The following definition, which encompasses the digital competencies that are required to effectively use digital curation tools, is more appropriate for this study: 'Curation can be summarized as an active process whereby content/artefacts are purposely selected to be preserved for future access. In the digital environment, additional elements can be leveraged, such as the inclusion of social media to disseminate collected content, the ability for other users to suggest content or leave comments and the critical evaluation and selection of the aggregated content. This latter part especially is important in defining this as an active process' (Antonio, Martin \& Stagg, 2012).

In response to the over-abundance of information now readily available on the internet, an emergent suite of digital tools, dubbed curation tools, have aligned themselves to the perceived need to locate, select and synthesize web content into open, user-organized collections. Scoop.it is one such tool that enables the user to select, preserve, maintain, collect and archive digital assets in one place. The user creates a Scoop.it account, selects a topic they are interested in, and curates digital content that is relevant to that topic. Scoop.it has additional functionality that allows the user to disseminate their content via the social media platforms that are embedded within the tool and suggest content to other users. Scoop.it has been integrated with both Facebook and Twitter to enable greater networking opportunities between users with similar interests. Users can also reuse content from other people's Scoop.it pages which is referred to as re-scooping. The researchers selected Scoop.it for this study as it adheres most closely to the aforementioned definition of curation. Scoop.it was incorporated into the curriculum to provide a forum for the students to connect with one another socially, whilst simultaneously exchanging information for educational purposes. 
Because Scoop.it is a public-facing site, the students were able to present their work to both their classmates and the wider community. This provided opportunities for ad hoc social interaction to occur and exposed students to possible experts in their chosen field who were curating similar topics, thus enabling the sharing of information resources in that area.

\subsection{Social Media Networks}

Social media can be defined as 'a collection of internet websites, services and practices that support collaboration, community building, participation and sharing' (Junco et al, 2010). Social networking sites, which fall under the collective term social media, include those where the user sets up a profile, creates formal connections to people they know, communicates and share preferences and interests with others. An essential feature of these sites is the capacity for user-generated content to enable sharing, co-creating, co-editing and co-construction of knowledge (Gunawardena, Hermans \& Richmond, 2009).

While Scoop.it is not strictly a social networking platform, it nevertheless facilitates the collaborative activities that are concomitant with social networking sites. In accordance with Antonio et al's (2012) definition, Scoop.it users create an account, which involves setting up a profile and choosing a topic around which to curate content. Scoop.it users can then search for individuals they know or individuals who are curating similar topics. The latter is more beneficial on this site as its central premise is the sharing of information resources. In order to reuse content from others, referred to as re-scooping, and suggest content to other users, the topics must have a degree of commonality. As such, in contrast to Facebook, which is built on the notion of finding friends, Scoop.it users find like-minded individuals with a similar topic focus, irrespective of whether or not they have an existing relationship with these individuals.

Social software applications provide platforms for many-to-many interactions, which enables community-based collaborative learning. They allow students to both present their 
own insights and consolidate and refine each others' contributions. Social software can, therefore, contribute to cognitive stimulation, relational exchanges, and facilitation of the learning process (Schroeder et al, 2010). Because students already spend a large portion of their time on the internet, particularly on social networking sites, institutions that embrace face-to-face online hybrid models can potentially leverage the online skills that learners already possess.

The integration of social media technologies into the curriculum is built on the premise that students want to use their personal social networking tools, such as Facebook and Twitter, in formal learning settings. However, there is little evidence to support such assumptions and further research is required to determine student expectations of ICT usage to support education, including the use of social networking technologies. Existing studies have observed a correlation between the use of educational technology and student engagement. Junco et al (2010) found that the use of Twitter in educationally relevant ways had a positive effect on student engagement. Amanda Rockinson-Szapkiw and Michael Szapkiw (2011) similarly observed that when Twitter aligns with lesson objectives, tweeting can be successfully used to facilitate learning and provide opportunities for educational collaboration in the classroom. Catherine McLoughlin and Mark Lee (2010) also noted that social software tools afford greater agency to the learner by allowing autonomy and engagement in global communities where ideas are exchanged and knowledge is created as students assume active roles. Each of these studies is grounded in self-regulated learning theory. Self-regulated learning (Biggs, 1987; Zimmerman \& Schunk, 1989; Simons 1992) refers to the learners ability to prepare for his/her own learning, to take the necessary steps to learn, manage and evaluate the learning, while simultaneously maintaining a high level of motivation. In these studies, engagement and self-regulated learning have been conflated. It has been assumed that students who are engaged are necessarily self-regulated learners to the 
extent that they are motivated to learn and thus invest additional effort in learning tasks.

While these studies acknowledge the potential of social networking technologies for increasing student engagement and self-regulated learning, they do not reveal whether or not students actually want to use social media sites for educational purposes. Research by Lisa Harris, Lorraine Warren, Jean Leah and Melanie Ashleigh (2010) indicated that students were uncomfortable with the application of social technologies in educational contexts, while Gail Salaway and Judy Caruso (2010) found that, while the use of social networking sites has increased to $95 \%$ for 18 and 19 year olds, only $30 \%$ of students in this study reported using social networking websites in their courses. Of this figure, half were using them to collaborate with other students about course-related matters and only 8\% reporting using them to communicate with instructors about course-related topics. George Siemens and Martin Weller (2011) similarly found that Facebook users who are attending university do not make much use of social networking platforms for educational purposes.

One of the consequences of utilizing social networking technologies in education is that it blurs the lines between our professional, personal and academic lives. Selwyn (2007) analyzed 68,000 Facebook wall postings by undergraduate students and found that only a small proportion of these posts were educational or university-related exchanges. The students in this study reported that Facebook should be used, firstly, for social purposes and, secondly, for informal learning purposes (student to student interactions about work-related matters), but not for formal teaching purposes (between staff and student involving formal assessment). When the students were asked whether or not Facebook could be used to enhance teaching and learning, 43\% responded negatively and explained that Facebook was a social networking site and not a tool for academic work. Selwyn concluded that when parents and lecturers inhabit social networking sites, it can create conflict for students as they struggle to know which face to present and often find communication stifled. 
The current study emerged in response to previous student evaluations which indicated that students wanted and expected a more interactive assessment task than a traditional essay. ICT students want more active, technology-based learning experiences, as is their chosen field, which are both social and participatory and supported by rich media. Although previous cohorts of ICT students have expressed a desire for Web 2.0 technologies to be embedded into the curriculum, the specific tools have not been identified and questions thus emerge with regards to whether or not this extends to social networking technologies: Do students want Web 2.0 technologies to be embedded into their coursework or do they prefer to separate work from play? Do students want to use their personal social media accounts for educational purposes? Do students want to engage with resources beyond those that are embedded in the institutions learning management system? This research explores these questions and attempts to shed light on how higher education students leverage Web 2.0 tools to enhance their learning experience.

\section{Method}

\subsection{Conduct}

258 higher education students from a first year, first semester Communications for ICT course constituted the participants of this study. The participants were given an assessment task that required them to create a Scoop.it page about an emerging area of ICT that they were interested in pursuing in their careers. They had to collect a minimum of five pieces of digital content to present on their Scoop.it page and, at the end of week four, the students submitted their Scoop.it URL to the lecturer. The students had a further two weeks to complete a 1000 word essay, which constituted the formal component of the assessment task. The students were able to use the resources they had accumulated on Scoop.it to inform their essay topic and to find further peer-reviewed sources, which were mandatory for the essay. In conjunction with the formal writing task, the students completed an annotated bibliography in 
which they were required to justify the five pieces of web-based content that they had included on their Scoop.it pages. If the students scooped more content than the minimum requirement, only five of the archived pieces needed to be qualified.

Part A of the assignment, the presentation of content on the Scoop.it page, was worth $10 \%$ and Part B of the assignment, the essay accompanied by the annotated bibliography, was worth $20 \%$. As part of the Scoop.it task, students were able to make comments, suggest content to others, and re-scoop content from other Scoop.it users. The students also had the option of integrating their Scoop.it accounts with their Facebook and/or Twitter pages to facilitate greater networking opportunities. However, for privacy reasons, this was not compulsory.

\subsection{Data Collection Methods}

To maximize the usefulness of the results, three sets of data were collected. By a process of triangulation (Yakel, 2007) the results of these data collection methods might be compared against the other, helping to validate or invalidate them.

\section{- Survey Questionnaire}

Following submission of the assessment item in week 4, students were asked to complete a survey that consisted of 21 questions. The anonymous survey was designed with Qualtrics and disseminated online and consisted of both multiple choice and open-ended questions. For Likert-scale items, student responses for Strongly Agree and Agree were collapsed and the same was done for Strongly Disagree and Disagree. The students were asked to indicate 'To what extent do you agree or disagree with the following statements.'

While the survey was designed to assess the students' overall experience of the Scoop.it task, two questions specifically asked students to evaluate the extent to which the Scoop.it task had enabled them to network with others. One of the questions asked students to indicate which statement best described how they networked with other students while the other asked 
students to rate the extent to which they agreed with a series of statements related to their networking behaviors. These two questions could then be compared to determine if the students' responses to these items were consistent. In order to strengthen the validity of the results, the students were also asked to indicate to what extent the Scoop.it task had enhanced their learning experience. In so doing, the researchers could distinguish between the students' experience with the digital curation tool itself and the networking potential of that tool. In addition to the multiple choice items, there were three open-ended survey questions which allowed the participants to provide additional comments.

\section{- Focus Group}

To supplement the survey data, six students volunteered to take part in the focus group, which consisted of six semi-structured interview questions.

1. Are you a regular user of social media tools such as Facebook and Twitter?

2. What were your reasons for choosing this course?

3. How did you choose the topic on which you scooped and why are you interested in that area?

4. Can you describe your experience of using Scoop.it?

5. Did you find Scoop.it useful to support your studies?

6. Is there anything else that you would like to add?

The students' responses to each of the above questions were transcribed. Content analysis was then undertaken in order to identify responses in which the theme of social networking was present.

\section{- Documentary Evidence}

The students were required to submit their Scoop.it URL to the course lecturer at the end of week four. For each student, the Scoop.it topic, the number of scoops (pieces of content they 
had collected), the number of re-scoops (pieces of content they had collected from another Scoop.it page), and the total number of items they had collected were calculated.

In so doing, the researchers were able to determine if there was any discrepancy between the students' responses to the survey items and their actual engagement with the Scoop.it platform. It was felt that using three data sources would serve to indicate a general trend which might be helpful to off-set the effects of students not giving sufficient thought to their survey answers, and also the possibility of selection bias, given the relatively small number of respondents $(\mathrm{n}=82)$ to the survey.

\section{Results}

\subsection{Survey Questionnaire}

Students were asked to indicate Which statement best describes how you networked with others on Scoop.it? Figure 1 shows the students' responses to this question.
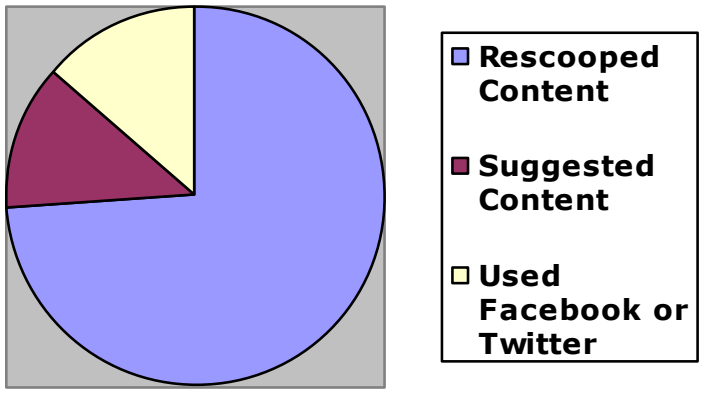

\section{Figure 1. Percentage of survey respondents who networked with others}

$71 \%$ of respondents indicated that they 're-scooped content from other Scoop.it users' and $12 \%$ 'suggested content for other Scoop.it users.' $13 \%$ of respondents indicated that they 'used Facebook and/or Twitter to share content with others.

Table 1 shows the students' responses to the following question: To what extent do you agree or disagree with the following statements?

Table 1. Student responses to the question: To what extent do you agree or disagree 
with the following statements

\begin{tabular}{|c|c|c|c|c|c|c|c|c|}
\hline Question & $\begin{array}{l}\text { Strongly } \\
\text { Disagree }\end{array}$ & Disagree & $\begin{array}{c}\text { Neither } \\
\text { Agree } \\
\text { nor } \\
\text { Disagree }\end{array}$ & Agree & $\begin{array}{c}\text { Strongly } \\
\text { Agree }\end{array}$ & $\begin{array}{c}\text { Total } \\
\text { Responses }\end{array}$ & Mean & $\begin{array}{l}\text { Standar } \\
\text { Deviatio }\end{array}$ \\
\hline $\begin{array}{l}\text { The Scoop.it } \\
\text { assessment task } \\
\text { has helped me } \\
\text { network with } \\
\text { other students in } \\
\text { this subject }\end{array}$ & 13 & 19 & 34 & 10 & 6 & 82 & 2.72 & 1.10 \\
\hline $\begin{array}{l}\text { Scoop.it has } \\
\text { helped me } \\
\text { network with } \\
\text { other students }\end{array}$ & 13 & 22 & 34 & 10 & 3 & 82 & 2.61 & 1.02 \\
\hline $\begin{array}{l}\text { The Facebook } \\
\text { function on } \\
\text { Scoop.it enabled } \\
\text { me to share } \\
\text { content I found } \\
\text { with others }\end{array}$ & 11 & 11 & 34 & 24 & 2 & 82 & 2.94 & 1.03 \\
\hline $\begin{array}{l}\text { The Twitter } \\
\text { function enabled } \\
\text { me to share } \\
\text { content I found } \\
\text { with others }\end{array}$ & 14 & 15 & 43 & 7 & 3 & 82 & 2.63 & 0.99 \\
\hline $\begin{array}{l}\text { The social media } \\
\text { functions on } \\
\text { Scoop.it helped } \\
\text { me network with } \\
\text { other students }\end{array}$ & 12 & 17 & 35 & 14 & 4 & 82 & 2.77 & 1.06 \\
\hline
\end{tabular}

These statements were designed to assess the networking methods used by the participants during this assessment task. A total of 82 responses were received (32\% of participants) and, of this figure, 16 students $(20 \%)$ agreed that the Scoop.it assessment task had helped them network with other students in that subject, while 32 (39\%) disagreed. $13(16 \%)$ respondents indicated that Scoop.it helped them network with other students compared to 35 (43\%) who did not think that it enabled them to network with others. $26(32 \%)$ students indicated that Facebook enabled them to share content with others compared to $22(27 \%)$ who disagreed. While $10(12 \%)$ participants used Twitter to share their content with others, $29(35 \%)$ did not. $18(22 \%)$ survey respondents indicated that the integration of social media platforms helped them network with other students, compared to $29(35 \%)$ who did not see the potential of 
social media for networking.

In order to assess the value of Scoop.it as a platform to improve the learning journey, students were asked to indicate the extent to which they agreed or disagreed with the following statements. Table 2 shows the students' responses to these statements.

Table 2: Student responses to the question: To what extent do you agree or disagree with the following statements

\begin{tabular}{|c|c|c|c|c|c|c|c|c|}
\hline Question & $\begin{array}{l}\text { Strongly } \\
\text { Disagree }\end{array}$ & Disagree & $\begin{array}{c}\text { Neither } \\
\text { Agree } \\
\text { nor } \\
\text { Disagree }\end{array}$ & Agree & $\begin{array}{c}\text { Strongly } \\
\text { Agree }\end{array}$ & $\begin{array}{c}\text { Total } \\
\text { Responses }\end{array}$ & Mean & $\begin{array}{l}\text { Standar } \\
\text { Deviatio }\end{array}$ \\
\hline $\begin{array}{l}\text { The use of Scoop.it } \\
\text { enhanced my } \\
\text { learning experience }\end{array}$ & 7 & 5 & 21 & 41 & 8 & 82 & 3.46 & 1.04 \\
\hline $\begin{array}{c}\text { I would take } \\
\text { another course with } \\
\text { a Scoop.it } \\
\text { component }\end{array}$ & 5 & 4 & 16 & 40 & 17 & 82 & 3.73 & 1.04 \\
\hline $\begin{array}{c}\text { I would use } \\
\text { Scoop.it in another } \\
\text { situation }\end{array}$ & 7 & 9 & 14 & 38 & 14 & 82 & 3.52 & 1.16 \\
\hline $\begin{array}{l}\text { I will be able to use } \\
\text { Scoop.it in my } \\
\text { future studies }\end{array}$ & 5 & 8 & 18 & 39 & 12 & 82 & 3.55 & 1.06 \\
\hline $\begin{array}{c}\text { Scoop.it is a } \\
\text { valuable research } \\
\text { tool }\end{array}$ & 7 & 6 & 14 & 45 & 10 & 82 & 3.55 & 1.08 \\
\hline $\begin{array}{l}\text { I will continue to } \\
\text { use my Scoop.it } \\
\text { account after the } \\
\text { assessment task is } \\
\text { completed }\end{array}$ & 9 & 11 & 27 & 27 & 8 & 82 & 3.17 & 1.13 \\
\hline
\end{tabular}

$49(60 \%)$ survey respondents agreed that Scoop.it enhanced their learning experience, whereas only $12(15 \%)$ participants disagreed. 57 (70\%) participants indicated that they would take another course with a Scoop.it component, compared to 9 (11\%) who said they would not. $62(76 \%)$ participants felt that they would use Scoop.it in another situation compared to $16(20 \%)$ who would not. When asked about whether or not Scoop.it could be used in their future studies, $51(62 \%)$ participants agreed and $13(16 \%)$ disagreed. 55 
participants believed that Scoop.it was a valuable research tool and $13(16 \%)$ participants did not. When asked if they would continue to use their Scoop.it accounts after the assignment was submitted, $35(43 \%)$ survey respondents indicated a desire to continue using their account and $20(24 \%)$ students said they would desist with the platform.

We examined students' answers to each of the three open-ended survey questions for themes regarding the networking potential of Scoop.it. One key theme emerged with regards to the networking affordances of Scoop.it: sharing resources with other students and the wider community. The students felt that Scoop.it was invaluable for sharing information resources with other students and the wider community. In the words of one respondent, 'I did find some really interesting articles and links from other users, which actually got me researching more widely.' Another student noted that 'Due to the open, social nature of Scoop.it, it is practical for media consumption and sharing with peers.'

\subsection{Focus group}

In response to question one (Are you a regular user of social media tools such as Facebook and Twitter?) each of the focus group participants indicated that they used social media tools such as Facebook and Twitter on a daily basis. In response to question four (Can you describe your experience of using Scoop.it?) one participant indicated that it is great to share resources with friends, although the platform is limited for social contact: 'I really liked that you can go to your friends articles and can share around each other's ideas and you can scoop their articles or they can scoop yours because that's a great way to gather information and get new ideas.'

In terms of the drawbacks of Scoop.it as a social networking platform, another of the focus group participants indicated that they did not feel a sense of social presence when using the platform. One of the shortcomings of 'Scoop.it was that I couldn't feel as much of a presence of other people's articles and what they were scooping. I wasn't actively searching for it but, 
just casually using it, I didn’t find any.' Another student acknowledged that although it would be possible to use the social networking channels to make social connections, 'I didn't really explore scooping other people's [Scoop.it articles], and the social network type approach.' This was a common theme within the focus group with another of the students similarly acknowledging that 'I didn't spend much time looking at other's people's scoops. I had a clear idea in mind about what I wanted to do and, honestly, if someone else had had the same information, I probably wouldn't have known.'

\subsection{Scoop.it pages}

Of the 258 students who completed Part A of the assessment task, only 22 students scooped the minimum five pieces of content. 236 students scooped a total of more than six pieces of digital content. Expressed as a percentage, $91.5 \%$ of students collected more than the five pieces of content that were required for the assessment task. 206 re-scooped content from another Scoop.it page and 52 did not. In percentage terms, $79 \%$ of students utilized the rescooping functionality of Scoop.it, while $21 \%$ did not.

\section{Discussion}

\subsection{Survey}

The results of this study suggest that Scoop.it enabled students to network with each other and the wider community for educational purposes, rather than for purely social reasons (i.e. not work-related). In response to the question Which statement best describes how you networked with others? $71 \%$ of respondents indicated that they 're-scooped content from other Scoop.it users', in order to accumulate resources for their own pages. In contrast, only $13 \%$ of respondents used Facebook and/or Twitter to share resources with others. If students wanted social networking technologies to be embedded into the curriculum then it might be expected that this figure would be higher. However, our findings indicate that students do not want to utilize their personal networking platforms for education, which supports previous 
research in this area which similarly found that students do not want to blend their personal and professional lives (Harris et al, 2010; Selwyn, 2007). This result must, however, be viewed with caution as the students were not required to connect their Scoop.it accounts with their existing social media platforms. The fact that only $13 \%$ of students elected to do so does not necessarily indicate that students do not want to use social media technologies in the classroom. It is equally plausible that the students found the assessment task sufficiently challenging without adding the social media component or, because it was not required for the assessment task, the students may have simply elected not to use the social media sites due the additional effort that this would have required.

In response to the question To what extent do you agree or disagree with the following statements, nearly half the respondents (43\%) indicated that Scoop.it had not helped them network with other students, while $32 \%$ of respondents said that Facebook had helped them share content with others. These findings suggest that students saw the value of Scoop.it for sharing information resources with others (educational networking) rather than as a tool for informal, social discussion (social networking). This further implies that students clearly distinguish between these forms of networking; the informal, non work-related, discussion that takes place on social media sites such as Facebook is distinct from collaborating and sharing resources. The results support previous research in the area, in which a correlation has been found between social software tools and opportunities to engage with global communities to exchange ideas and share knowledge (McLoughlin \& Lee, 2010). That is, the students saw the value of Scoop.it for enhancing the learning experience by sharing information, rather than as a tool for networking with other students and the wider community in a purely social sense.

The second series of statements (Table 2) was designed to assess the value of integrating Web 2.0 technologies into the curriculum more broadly. $70 \%$ and $76 \%$ of the survey 
population respectively would elect to use Scoop.it in further studies or as an informal learning tool. This supports existing research, which has found that social media platforms enable students to interact with each other around academic issues when they are used in educationally-relevant ways (Junco et al, 2010). Moreover, and in an attempt to shed light on the questions asked at the commencement of this research, the results suggest that higher education students want Web 2.0 technologies to be embedded into coursework, but not necessarily their personal social media accounts. This cohort of students appear to distinguish between interactive learning experiences that allow them to network and collaborate with materials and experts outside the learning management system and social media sites, which students use to socialize in their personal lives.

\subsection{Focus group}

The focus group question Can you describe your experience of using Scoop.it, yielded a number of responses that highlighted the educational networking potential of the digital curation platform. The focus group participants were divided between those who saw Scoop.it as an informal knowledge sharing platform and those who did not see the potential of the tool for facilitating a sense of social presence among the students. This reiterates the findings of the survey questionnaire in terms of the distinction that students make between social and educational networking. Although students saw the value of Scoop.it for sharing information resources ('I would come to uni and then go home to it and see what other people have scooped and see if it's relevant to me and then I could re-scoop it onto my page'), this did not equate to a sense of opportunity for socializing with others about non-work related issues: ('I couldn't feel as much of a presence of other people's articles and what they were scooping. I wasn't actively searching for it but, just casually using it, I didn’t find any'). Rather than using Scoop.it as a tool for communicating with others in a purely social sense, the value of the network in terms of learning is the access that Scoop.it provides to a web of 
information sources offering multiple perspectives and dialogues, help from others, and the co-creation of knowledge.

\subsection{Scoop.it pages}

Previous research (McLoughlin \& Lee, 2010; Rockinson-Szapkiw \& Szapkiw, 2011) in this area suggested that the integration of Web 2.0 tools into the curriculum facilitated selfregulated learning and our findings likewise showed a correlation between the use of Scoop.it and effort invested to complete the assessment task. In the current study, $91.5 \%$ of students collected 6 or more pieces of digital content. This suggests that the use of the digital curation platform motivated the students to put additional effort into the task. This supports previous research in the area, which suggests that the integration of public, internet-based applications into the curriculum encourages students to put extra effort into the task because these sites can be accessed by the wider public. McLoughlin and Lee (2010) similarly observed that social software tools afford greater agency to the learner by allowing autonomy and engagement in global communities where ideas are exchanged and knowledge is created as students assume active roles. The implication is that the unique combination of showcasing one's work to the wider public and giving students a degree of ownership and autonomy in learning tasks motivates the student to invest greater effort in the completion of the assessment item and encourages self-regulated learning.

Aside from the integration of Scoop.it with social networking sites such as Facebook and Twitter, the frequency with which the students re-scooped content from other Scoop.it pages is evidence of the educational networking potential of this platform. 206 out of 258 students re-scooped content from other users. In order to do this, the user has to actively search for other Scoop.it pages on a similar topic area from which they can draw on and reuse contentreferred to as re-scooping-for their own pages.

$79 \%$ of students who submitted Part A of the assignment re-scooped content from other 
Scoop.it pages. As it was not mandatory for the students to re-scoop content for the assessment task, the findings from this study suggest that students were engaged with the platform and were motivated to share content with others who had similar interests. While the social networking platforms (Facebook and Twitter) were not well utilized by the participants, the opportunity to share resources and information relevant to their topic area was welcomed by the students. Scoop.it may not have been used by the students to communicate on an exclusively social level (social networking), but the value of Scoop.it as an educational networking platform was borne out by the results of this study.

\section{Conclusion}

This study explored the potential of the digital curation platform Scoop.it as a networking tool in a first year, first semester, ICT course. The results of this project suggest that while Scoop.it was invaluable as an information sharing platform that enabled the students to share their ideas and resources with others who were collecting resources in a similar area (educational networking), its potential as a tool for socialization (social networking) was less apparent. Scoop.it was found to be a useful tool to supplement campus-based interaction; however, it was used by the students predominantly for the purpose of finding content that was relevant to the topic they were curating, rather than as a tool for social communication. Moreover, the fact that only a small proportion (13\%) of students elected to utilize Facebook and/or Twitter suggests that this cohort of students did not want to use their personal social media accounts in an educational setting. This result should, however, be viewed with caution as the students were not required to integrate their Scoop.it accounts with these social networking platforms in order to successfully complete the assignment. In future research, it would be interesting to explore the value of Scoop.it for creating social connections by making it mandatory for the students to integrate their Scoop.it accounts with their Facebook and/or Twitter profiles. 
As social software applications allow large numbers of students to not only present their own insights but also consolidate and refine each other's' contributions, the enthusiasm about the potential impact of these applications for teaching and learning seems to be well justified. Scoop.it facilitated the creation of new connections because it gave students an alternative means of connecting with others with whom they share interests or goals. However, these connections may be limited to educational networking in the sense that students communicate with like others for the purpose of sharing information resources, rather than for establishing friendships.

\section{References}

Antonio, A., Martin, N., \& Stagg, A. (2012). Engaging higher education students via digital curation, Proceedings ascilite Wellington 2012. http://www.ascilite2012.org/page.php?31

Biggs, J. (1987). Student approaches to learning and studying. Hawthorne, Vic.: ACER.

Ebner, M., Lienhardt, C., Rohs, M., \& Meyer I. (2010). "Microblogs in higher education - a chance to facilitate informal and process-oriented learning", Computers and Education, Vol. $55,92-100$.

Gunawardena, C., Hermans, M., \& Richmond, C. (2009). "A theoretical framework for building online communities of practice with social networking tools", Educational Media International, Vol. 46, No. 1, 3-16.

Harris, L., Warren, L., Ashleigh M. (2010). Small steps across the chasm: ideas for embedding a culture of open education in the university sector. Education, 16(1). http://www.ineducation.ca/article/small-steps-across-chasm-ideas-embedding-culture-openeducation-university-sector [Online].

Hughes, A. (2009). Higher Education in a Web 2.0 world. JISC Report. http://www.jisc.ac.uk/media/documents/publications/heweb20rptv1.pdf.

Junco, R., Heiberger, G., \& Loken, E. (2010). "The effect of Twitter on college student engagement and grades", Journal of Computer Assisted Learning, Vol. 27, No. 2, 119-132.

McLoughlin, C., \& Lee, M. (2010). "Personalized and self-regulated learning in the Web 2.0 era: International exemplars of innovative pedagogy using social software", Australasian Journal of Educational Technology, Vol. 26, No. 1, 28-43.

Rockinson-Szapkiw, M., \& Szapkiw, M. (2011) Engaging higher education students using Twitter, Proceedings Global Learn Asia Pacific, http://digitalcommons.liberty.edu/cgi/viewcontent.cgi?article $=1205 \&$ context $=$ educ_fac pubs, 
$360-364$.

Rosenbaum, S. (2010). Why Content Curation is Here to Stay, http://mashable.com/2010/05/03/content-curation-creation/

Russo, A., Watkins, J., \& Groundwater-Smith, S. (2009). "The impact of social media on informal learning in museums", Educational Media International, Vol. 46, No. 2, 153-66.

Salaway, G., \& Caruso, J. B. (2010). The ECAR study of undergraduate students and information technology. Boulder, Colorado: EDUCAUSE Center for Applied Research.

Schroeder, A., Minocha, S., \& Schneider, C. (2010). "The strengths, weaknesses, opportunities, and treats of using social software in higher and further education teaching and learning", Journal of Computer Assisted Learning, Vol. 26, 159-174.

Scime, E. (2009). The Content Strategist as Digital Curator, http://www.dopedata.com/2009/12/08/the-content-strategist-as-digital-curator/

Selwyn, N. (2007). Screw blackboard...do it on Facebook!: An investigation of students' educational use of Facebook. Paper presented to the Pole 1.0 - Facebook social research symposium, November 15, at University of London. http://www.scribd.com/doc/513958/ Facebook-seminar-paper-Selwyn (accessed September, 2008).

Siemens, G., \& Weller, M. (2011). Higher education and the promises and perils of social network. Revista de Universidad y Sociedad del Conocimiento (RUSC), 8(1), 164-170.

Simons, P. R.-J. (1992). Constructive learning: The role of the learner. In T. M. Duffy, J. Lowyck, D. Jonassen \& T. M. Welsh (Eds), Designing environments for constructive learning (pp. 291-313). Berlin: Springer-Verlag.

Wheeler, S (2011). The Great Collective, http://steve-heeler.blogspot.com.au/2011/07/greatcollective.html\#!/2011/07/great-collective.html.

Yakel, E. (2007). Digital Curation,Emerald Group Publishing Limited,23(4), 335-340.

Zimmerman, B. J. \& Schunk, D. H. (Eds) (1989). Self-regulated learning and academic achievement: Theory, research and practice. New York: Springer-Verlag. 